\title{
The Costs and Benefits Analyses of Peg Regime with Indian Currency
}

\begin{abstract}
Akshar Nepal* and Nagma Pokharel*
Abstract

This paper aims to provide a comprehensive idea on peg regime where its actual costs and benefits have been analyzed. The object of the study is to give an overview towards the country's economy and where it is facing due to the involvement of peg regime. Many reviews have been accomplished in this matter and people have written a lot about the peg regime, also about its misalignment. But after consultation with the scholars and traders anything spoken would not be valid unless it has been presented with empirical analysis for any kind of change to be forwarded in order to review the existing peg regime. This paper has solely highlighted the cost and benefits and it does not challenge any economists or scholars who have different views regarding the matter.
\end{abstract}

Key words: Peg regime, cost, benefit, Nepalese currency, Indian Currency 


\section{Background}

The peg regime has been carried on from the establishment of Nepal Rastra Bank and before that Nepalese currency (NC) had less sovereignty and both Indian currency (IC) and NC were used for daily transaction with dual currency system. Basically, when we talk about peg we have to keep in mind that pegging is practiced to stabilize the economy.

A fixed exchange rate, also known as pegged exchange rate (Buddha, B. B., based on a personal interview on April $15,2016)$, is a kind of exchange rate where the value of a currency is fixed with a single currency or a basket of other currencies. The pegging is practiced to stabilize the value of a currency and its peg does not change based on market conditions in contrary to floating currencies. It is also a means to control the behavior of a currency, also by limiting the rates of inflation. In the context of Nepal, Nepal Rastra Bank (NRB) helps stabilize the peg motivated 
by a futuristic intention to maintain better exchange rate of the national currency in the international market by the help of relatively powerful regional currency, i.e., Indian currency.

Indian government devalued its currency but at the meantime, Nepalese currency was to stay where it was as a result of being pegged with the new exchange rate, Nepalese currency 101 equivalent to Indian rupees 100. As the matter of this, the impression created by the peg by IC is not in Nepal's national interest due to which many efforts have been made to remove the provision. But shifting to floating rate would increase the instability in Nepalese economy (Jha, 2011). In other words, it is to be noted that there has been a lot of fluctuation in the Nepalese economy due to which reviewing the peg in this period of time is not justifiable leading to more disturbance in the balance of payment.

International Monetary Fund ([IMF], 2011) has highlighted Nepal's high inflation, widening trade deficits and erosion of international competitiveness due to the pegged exchanged rate with India. Even though the peg is to keep the inflation tie-up, the Nepalese inflation is not exactly moving with Indian non-food inflation. IMF (2011) has identified an appreciation of the real effective exchange rate (REER) by 8 percent on an average in the year 2010-11 compared to that of 2009-10. The overvaluation of the Nepalese currency by 14.4 percent, 20.2 percent and 19.1 percent was observed using three different approaches -- Macro Balance (MB), External Sustainability (ES) and Purchasing Power Parity (PPP). In spite of the overvaluation, the peg is considered to be a stable and transparent firmly.

\section{Aim}

Nepalese economy has various drawbacks and one of the many is our volatile market. The peg carried on has not been reviewed even with various considerations which are due of lack of ability to stability and stability to ability of the market. The main motive of this review is to perform an assessment of the present position of the Nepalese economy and currency power in the changing global contexts.

It is very important to understand the global best practices of peg system of 
currency exchange rates. Many strong economies who have had two digit growth rates from past few years have adopted the peg regime which has benefited their economies from various aspects:

a. analyze the causes and consequences of effective peg implementation in context of Indo-Nepal economic exchanges,

b. predict a more sustainable durability of peg system of currency exchange between India and Nepal, and

c. analyze the effects and long term outcomes of effective management of peg regime.

\section{Statement of the Problem}

The general observation of the national scenario on economic issues by means of exploration of the available literature opened up a dilemmatic scene in relation with causes and consequences of the peg system based exchange regime between the $\mathrm{NC}$ and the IC as the earlier studies have been found to be quite contradicting to each other. Meaning that of a group of scholars favored the peg system, the general exploration witnessed another group of scholars going against the idea of peg, and none of these groups could come up with universally acceptable proposition. This dramatic scene provoked the present researcher in taking up this matter as a subject of empirical enquiry - What, if the peg system is favorable for the Nepalese economy keeping in view the long term perspective of sustainable economic development?

Hence, the present researcher aimed to fulfill the required gap in a practice with empirical analysis whether the peg is to be carried on which is an important aspect to be realized that it has sustained the Nepalese economy or if there has been other aspect stabilizing the economy. Also, the inflation related aspect that is brought though Indian economy is to be highlighted for how it is to be controlled, if necessary and possible.

In course of enhancing the selfdevelopment skill competence in the field of peg system, the present researcher views to enroll into the complete analysis upon the misalignment of peg exchange $\mathrm{r}$ e $\mathrm{g}$ i $\mathrm{m} \mathrm{e}$ 
and establish empirical differences accordingly. Moving along the researcher's motive is to give a bird eye over the impact of misalignment of peg system in the balance of payments (BOP) account.

\section{Materials and Methods}

The main purpose of developing this chapter is to empower the present researcher's level of cognition in a respective field of study from mainly three perspectives - understanding of conceptual and theoretical aspects linked to peg system of currency exchange, having revisit of related policy documents, and reviewing other related studies performed in past, especially in the field of peg regime. For this, the subsequent three sections of the chapter deal on these aspects in a chronological order. Finally, on the basis of overall learning from such reviews, the present researcher has developed a conceptual framework with an aim to govern the ongoing research in a more technically systematic and conceptually grounded manner. Such a framework has been presented in the fourth section of this chapter.

\section{Review of Theoretical}

\section{Perspective}

As part of the main body, review of literature section provides closer study of various theoretical and conceptual aspects related factors responsible for peg system that is carried on with Nepalese currency that influence trade and transit and overall economic activities within the country. The works of Wang (2009), Panday (2015), Hill (2009), Ghosh, Gulde \& Wolf (2002), Dahal (2004) served instrumental in acquiring depth knowledge of the related theoretical and conceptual constructs to make the study theoretically grounded.

\section{Exchange Rate classification}

Exchange rate is categorized under completely free floating or flexible while on the other side it can be leveled as pegged or fixed to one of the strong currencies or basket of currencies Wang (2009). Since the breakdown of Bretton Woods's system the people have mainly been shifting from one regime to the other. Floating their currencies without linkage has mainly been practiced. To look into this can further be elaborated with different categories IMF has established for the free floating 
and peg regimes. Also, the classification has been based under the flexibility of the categories. The arrangement of these exchange rates focuses over choice of exchange rate regimes to the independence of monetary policy but it is to be noted that a complete independence of monetary policy from exchange rate policy doesn't exist under and exchange rate regime. In observing the debates about peg regime there have mainly been two substantial differences as hard peg and soft peg. Nepal follows the conventional peg all along with countries like Bhutan, Qatar, Denmark and others. This can further be viewed with different arrangements. Classification of exchange rate arrangement has been kept here under hard peg, soft peg and floating. Nepal follows the conventional peg all along with countries like Bhutan, Qatar, Denmark and others.

\section{Choice of Exchange Rate}

To make a choice on which exchange rate regime is followed is considered one of the major unresolved questions of worldwide macroeconomics. Whether to keep on with hard peg or free float the currency in the international market is the major comeback awaited for the question of every worldwide economy (Panday, A, 2015). Peg cannot be absolute viable under too much of capital mobility unless the country makes an absolute commitment towards it. Almost half of the countries in IMF has withdrawn peg and followed free floating (Hill C.W.L, 2009).

\section{Cost and benefits of}

\section{Peg Regime}

Peg exchange rate regime has a benefit on inflation which means it has lower rated inflation on run-of-the-mill. The differential classification between the two declines from $10^{1 / 2}$ to 7 percentage points per year in the de jure classification and from $21 \frac{1 / 2}{2}$ to 15 percentage points per year in the consensus classification (Ghosh, Gulde $\&$ Wolf , 2002).

\subsubsection{Nepal and India: Open Border Relation}

In the words of Thapa (2004), "It has been found that Nepalese prices tend to follow closely the Indian prices because of open border, fixed exchange rate regime and significant share of Nepal's trade with India". The researchers 
comprehend that, the relationship here is deep and complicated. This means Nepal carried India's part of inflation along. This also means this relationship is not new and yet hard to degrade or leave somewhere. Pegged exchange rate has been a part of inflation carrying medium to the Nepalese economy.

\section{Sources of Information}

As a pond of exploration, the researchers had an interaction with Dr. Gunakar Bhatta, who has been serving as the director at Nepal Rastra Bank. In addition, the description component of the conclusive research design used in the present study for statistical testing as present researcher will develop a set of questionnaire to assess the prevailing awareness of Nepal.

Likewise, from secondary sources, the present researcher had reviewed various books, journals published by NRB: an econometric analysis of the impact of real effective exchange rate on economic activities in Nepal, economic factors influencing the probability of adjustments in Nepal's exchange rate policy with the Indian currency, IMF Working Papers, The World Bank : Choice Of Exchange Rate Regimes For Developing Countries articles published by IB, and different published documents of various scholars from NRB and renowned economists as well as institutions and industrialists.

\section{Perception on Peg Regime}

There are certain foundations for currency to be pegged with one another and there are basically three factors. First one being trade. Peg regime is practiced to make the trade smooth. When a currency is pegged with the other it stabilizes the other currency making the trade happen in one rate for all the time i.e. 1:1.6. Trade is the main factor for peg regime especially in Nepalese context. We so face a lot of trade deficit and BOP is balanced with the incoming remittances every day. Export is not able to cover the loss we bear as due to lack of the level of goods and services matching the international level. So, the fixed rate of trading is possible due to peg regime has made the economy stronger.

The second factor is investment. The Foreign Direct investment (FDI) coming 
from various countries can be uplifted with the peg regime. This further stabilizes the value of Nepalese currency and also helps in gaining trust of investors upon it. Peg is practiced to gain the trust of foreign investors and it benefits the country in various aspects. FDI allows the transfer of technology particularly in the form of new varieties of capital inputs that cannot be achieved through financial investments or trade in goods and services. FDI can also promote competition in the domestic input market. Recipients of FDI often gain employee training in the course of operating the new businesses, which contributes to human capital development in the host country. Profits generated by FDI contribute to corporate tax revenues in the host country.

The cost and benefits of peg regime could be highlighted with few points. The benefits being business confidence, smooth trade, cross border transaction linkages being smooth and people being equally confidence with $\mathrm{NC}$ like with IC. Business men tend to have the greater amount of confidence as what they invest upon would yield return with no fluctuations in the rate of NC. The country could practice smooth trade and the transaction between two countries would be more reliable and trustworthy.

While the costs experienced are also of the same respect. International shocks upon Indian economy would lead corresponding pressure (unwanted shocks) resulting to serving other currency need and lack of independence in our macroeconomic policy. Leading to strong currency valuation for Nepalese currency due increase in foreign reserve has not been possible due to devaluation of Indian currency which had occurred in past and can also be seen in future. Since we have to walk along with the international shocks India bears we cannot face the reality of our economy, we may confirm this with past data.

But in spite of this we still value the peg system because this is temporary appointment and we assume this is going to be clear in long run scenario and that has been happening. Like now we got strong BOP our currency is not devaluating. The EU problem right now 
"we do not have any valuation with EU

SO

in the case, Indian currency lost its valuation means we lost the value as well but taking it as a temporary instability we value to take the peg further".

Although, with all the cost along with benefits Nepalese economists still prepare the economy to the peg regime because we do not practice it, then it results to cross border trade instability as the matter of prediction where Nepalese currency might lose its valuation and start holding IC. The problems may be:

1. Traders need to run their transaction in a speculative way.

2. Increase in transaction cost, most importantly problem in price.

3. Peg is also important for price stability because as we remove the peg due to unwanted shocks, price increases with the decrease in currency valuation but later even if the Nepalese currency valuation increases price doesn't go down as it runs with certain trend.

4. Also, economy integration suggests that peg is the reality and the benefits are higher for the economy.
As many economists have suggested in reviewing the peg, no argument can be justified without empirical evidence. It 
should be monitored as a sensitive matter as, if things go wrong, it is hard to bring it back to where it was. So when economists speak they have to articulate with empirical evidence alongside. The personalities claim that academic exercise is good but practically not valid to remove the peg.

We may ask the question when would be the right time for the currency revaluation or reviewing the peg regime. There needs to be certain time when that can finally be practiced. The first priority is when the economy is strong. When we talk about strong economy we mean high level of growth, employment and infrastructure governor also alarmed about the low price that needs to be maintained. Lower price helps to compete in international market if not then the product is less preferred. Low price enables more demand for the good resulting to higher export of goods and incoming foreign currency resulting to increase in foreign reserve in central bank.

Other condition could be financial stability. The scholar suggested that in the period of volatility, market should not be moved which would provoke the market leading counter productivity. Hindering what is there rather than development as well. We further imply that strong economy has high export and a surplus in BOP. It also means good governance and good plans in every good or bad conditions or shocks that it can take itself and survive without any help.

The second condition should be stable market place. Frequent fluctuation in market place is another reason for peg to be carried on. Various disputes and lack of trust on peg regime has made it more difficult for the $\mathrm{NC}$ to perform in international market. The former gaining something new could be the result down here. So everything needs to be analyzed properly before jumping into any kind of conclusion.

Nepalese economy did face few obstacles from peg regime from the time it started. According to Yuv Raj Khatiwada, "In Monetary policy, we cannot keep the money supply in our target. There was increase in reserve, but if exchange rate could clear the increased reserve, there would have been no problem but as the matter of fact it doesn't result towards flow of money in 
the market and affect monetary policy". In spite of this our monetary policy doesn't affect the price in a critical way; the only thing that it affects is the autonomy of central bank as it targets money supply.

\section{Conclusion}

The peg regime that has been practiced since 1960 A.D has been going on and has not been reviewed since the year 1993. Economists argue that peg is the reason for stability in the trade and reliability upon Nepalese currency as well. Indian economy has been fluctuating and the value of other currencies is derived from IC to NC. As the matter of fact the foreign exchange rate is determined on the basis of Indian economy. The increase or decrease in the price of dollar is always on the basis of Indian economy fluctuations for Nepal.

The economic benefits or the crash, the economy faces has nothing to do with increase or decrease with the price of dollar or any other foreign currency as long as it if pegged with IC. Demand and supply are responsible for other calculations. The peg definitely has stabilized the economy and brought 
growth but it has also carried inflation all along making the macroeconomic policies dependent.

\section{REFERENCES}

Abonyi, G. (1999). Thailand: from financial crisis to economic renewal. Institute of Southeast Asian Studies.

Cooper, D.R., \& Schindler, P.S. (2006). Business research methods. $\left(9^{\text {th }}\right.$ ed.). New Delhi: Tata McGraw Hill Education Private Limited.

Dahal, M. K. (Ed.). (2004). Nepalese economy: Towards building a strong economic nation-state. Central Dept. of Economics, Tribhuvan University and New Hira Books Enterprises.

Ghosh, A. R., Gulde-Wolf, A. M., \& Wolf, H. C. (2002). Exchange rate regimes: Choices and consequences (Vol. 1). Mit Press

Hari Bansh Jha, (2011). ICCR fellow based at Institute of Defense Studies and Analysis.

Hill, C. W. (1998). The Asian financial crisis. Unpublished manuscript. University of Washington, Seattle, Washington

IMF Publication Service, 2011 IMF Inflation Dynamics in Nepal. Report No. 11/319
Maskay, N. (2007). A Study of the Trends in the Nepalese-Indian Currency Exchange Rate during the Period of 1932-1960 (No. 03/2007). Nepal Rastra Bank, Research Department.

Meese, R. A., \& Rogoff, K. (1983). Empirical exchange rate models of the seventies: Do they fit out of sample?. Journal of international economics, 14(1), 3-24.

Panday, A. (2015). Impact of Monetary Policy on Exchange Market Pressure: The Case of Nepal, Journal of Asian Economics, http://dx.doi.org/10.1016/j.asieco .2015 .02 .001

Thapa, N. B. (2002). An econometric analysis of the impact of real effective exchange rate on economic activities in Nepal. Economic Review: Occasional Paper, 14, 17-36.

X. Wang, K. Guo, X. Lu, The long-run dynamic relationship between exchange rate and its attention index: Based on DCCA and TOP method, Physica A (2016), http://dx.doi.org/10.1016/j.phys a.2016.01.092 